\title{
Nanoemulgel: a Promising Nanolipoidal-Emulsion Based Drug Delivery System in Managing Psoriasis
}

\author{
Snigdha Bhardwaj and Ashutosh Tiwari \\ I.T.S College of Pharmacy, Murad Nagar, Ghaziabad, U.P. (201206), India \\ (Received: February 26, 2021, 2021; Accepted: September 16, 2021; Published (web): October 14, 2021)

\begin{abstract}
Nanomedicine, a novel concept, bears much hope in delivering drug candidates having low solubility and bioavailability. Nano-emulgel, one of the emerging tools, is considered as ideal carriers for the topical delivery of lipophilic drugs to overcome these challenges in the management of psoriasis and related skin problems. Psoriasis is an auto-immune and chronic inflammatory disease affecting 2-3\% population of the world. Current available treatment of psoriasis has limitations such as systemic side effects and low percutaneous permeation, which evokes a dire need to develop an alternative lipoidal nanocarrier system. Nano-emulgel is basically formed by admixing nanoemulsion system with a hydrogel matrix using both high and low energy methods. Various literatures have been and better bioavailability of lipophilic drugs with nano-emulgel delivery via topical route. Several approved marketed preparations are available that strongly support the stability of these nanocarriers in respect to its efficacy and safety. This supports the fact of using topical nano-emulgel system to deliver lipophilic drugs to overcome the sufferings from oral delivery and improved patient compliance. Therefore, it is suggested as a potential system that can be used for an effective management of psoriasis via topical route in near future.
\end{abstract} \\ reported for lipoidal nanocarriers in topical treatment suggesting reduced dose, improved percutaneous absorption
}

Key words: Topical route, nanotechnology, nano-emulgel, lipophillic drugs, bioavailability, skin disease, psoriasis

\section{INTRODUCTION}

Psoriasis is a chronic, T lymphocyte (T-cells) mediated auto-immune inflammatory condition identified by abnormal, rough and red-coloured blotch on skin due to epidermal hyper-proliferation and mostly affects knee, elbow, trunk and scalp. ${ }^{1}$ The prevalence of the disease is about $2 \%$ worldwide but varies according to regions. The disease incidences are comparatively low in population of Asia and Africa and higher in Caucasian and Scandinavian population. $^{2}$

Tumour necrosis factor- $\alpha$ (TNF- $\alpha)$ binds to receptor present on keratinocyte that activates hyper proliferation. Interlukin 23 (IL23) plays a crucial role in psoriasis and helps in differentiation of Th17cells

Correspondence to: Snigdha Bhardwaj

E-mail: snigs.16@gmail.com

Dhaka Univ. J. Pharm. Sci. 20(2): 235-246, 2021 (December)

DOI: https://doi.org/10.3329/dujps.v20i2.57174 and produce IL23, IL22. Psoriatic plaque shows high level of vascular growth factor which increases angiogenesis results bleeding point when peeled off. ${ }^{3}$ Psoriasis is derived from Greek word "psora ", means itch and joints and tendons are affected along with itchy sensation on the body. In psoriasis both the environment and inherited factors play important role to cause the disease. Stress, damage to skin, alcohol, and exposure of sunlight may cause psoriasis. Also, some medications given in high blood pressure (BP), angina and malaria may worsen the psoriatic condition. In patients with smoking habit and obesity, the treatment of psoriasis is very difficult. ${ }^{4}$ Main symptoms of psoriasis are red skin, crusty patches causing intense itching, burning sensation and discomfort. Psoriasis can be mild, moderate and severe in respect to the coverage of body skin. Mild psoriasis covers less than $3 \%$ of body, moderate 
psoriasis covers $3-10 \%$ of body and severe psoriasis covers more than $10 \%$ of body. ${ }^{5,6}$ Psoriasis being an auto-immune disease, CD8 \& CD4 T cells play an important role and has specificity towards cathelicidin peptide (LL37) and stimulates the secretion of IFN-1 and pro-inflammatory factors in severe to moderate patients with psoriasis. ${ }^{7,8}$ The psoriatic condition may be categorized into various sub-types as mentioned below. (i) Plaque psoriasis involves raised and inflamed skin, covered by silvery, white scales of elbows, knees, lower back. About 8090\% people suffer from this type of psoriasis; (ii) Inverse psoriasis develops as localized skin-folds, area groin, under breast, skin fold, and armpit. A red lesion, without scaly patterns occurs in obese patient having deep skin fold ${ }^{9}$ and (iii) Erythrodermic psoriasis is rare inflammatory condition covering redness associated with large area across body surface. It has exfoliation, peeling of skin and leads to pneumonia, and heart failure. The confirmation of this type of psoriasis can be done by pityriasis rubra pilaris (PRP) erythroderma ${ }^{10,11}$; (iv) Guttate psoriasis mainly occurs in childhood or young adulthood and appears like small, red, spot in skin causing conditions like, stress, injury to skin, and respiratory infections. This type of psoriasis is associated with HLA-Cw6 gene abnormality. Lesions can be seen in scalps, faces part of skin and become regress in 3 to 4 months ${ }^{12}$; (v) Pustular psoriasis affects adults more than children. It appears like white pustules, red skin and affect certain areas of body. ${ }^{5}$ Abnormal body immune response provokes the development of psoriatic inflammation. Activation of innate immune system occurs by endogenous auto-inflammatory signals exists in some patients. The inflammatory milieu activates keratinocyte proliferation via TNF- $\alpha$, IL-17, and IFN- $\gamma$. Pustular psoriasis is characterized by increasing expression of IL-1 $\beta$, IL-36 $\alpha$, and IL$36 \gamma$; IL-17 signalling involved in pustular psoriasis occurred in patients. The psoriatic arthritis (PsA) and psoriasis are inter-related heritable disorder as synovial tissue in psoriatic arthritis expresses proinflammatory cytokines: IL- 1, IFN- $\gamma$, and TNF $\alpha .^{13-15}$ For the treatment, psoriasis is divided into localized and generalized forms depending upon the area of the body surface exposed and condition of the area involved. For generalized disease, systemic therapy like, oral therapy and ultraviolet-B (UVB) photo therapies have been used for the effective treatment of psoriasis. For localized disease (defined as covering $<10 \%$ of body surface area) topical therapy is required to improve quality of treatment with minimal side effects. ${ }^{16}$

Topical route simply acts as carrier in which the drug is delivered through skin as to show the effect at the site of administration for various cosmetics and dermatological products. ${ }^{17,18}$ The skin is the largest organ of body and has been an excellent medium for topical applications for a variety of drugs in achieving the desired therapeutic performance in several skin disorders. They can be used as an alternative approach for those drug candidates having problems associated with oral route such as hepatic first pass metabolism, low bioavailability, low solubility etc. that lead to reduced patient compliance. ${ }^{19}$ Permeation of drug molecule can be achieved through the skin layers that include sebaceous follicle, sweat duct, stratum corneum. ${ }^{20}$ Drug absorption through the percutaneous membrane may be affected by major factors such as role of concentration gradient in which the passage of drugs through skin involve driving force, diffusion and partition coefficients. Drug with low molecular mass have high solubility and thus partition coefficient is increased. ${ }^{21}$ Topical drug delivery can be categorized into two types namely (i) External delivery refers to drug is being delivered into the cutaneous tissue to have action on the affected area and (ii) Internal delivery represents the drug applied on to the mucous membrane or tissues on localized area.The drug needs to cross the skin barriers to achieve the targeted concentration at the site of action and to reach in circulation. ${ }^{22}$ Among all the novel nano-lipoidal delivery systems, nanoemulgel is considered to be the most effective delivery system for topical application of drugs with high lipophilicity and low systemic availability or both. The system is suggested to improve pharmacokinetic behavior of drug candidates such as BCS II/IV (Biopharmaceutical Classification System) drugs in respect to solubility, 
permeability and bioavailability via the topical route. ${ }^{23,24}$ The nanoemulgel system is believed to exhibit quicker and early healing of psoriasis due to its deep penetration in skin and longer duration of action of drug candidates as compared to conventional topical gels. Thus, nano-emulgel can be considered a promising system for the better longterm management of psoriasis. ${ }^{25}$

\section{METHODS}

This paper aims to present a systematic review on nanoemulgel, a novel drug delivery system and its applications. In addition, possible trends, therapeutic potential and future prospective of nanoemulgel in effective management of psoriasis are also briefly discussed. For this, scientific literatures were systematically searched for data using library catalogs and also online databases such as Web of Science, Scopus, Wiley Online Library, Science Direct, Pubmed/Medline and Google Scholar. The literature was searched by using key words such as "nanocarriers", "nanoemulgel", "psoriasis", "nanoemulgel for treating psoriasis", and "marketed nanocarriers for treating skin problems". Only peer reviewed scientific journals following inclusion criteria were considered for data compilation during the review process.

\section{RESULTS AND DISCUSSION}

A nano-emulgel system is an admixture of nanoemulsion with a gelling agent. The water content of gel facilitates the conversion of nanoemulsion into nano-emulgel maintaining the size of droplets in the range of 5-500 nm. ${ }^{21,22}$ During preparation of nanoemulgel, various gelling agent are added to the nanoemulsion to increase the stability of formulation and reduce surface and interfacial tension for drugs to be delivered topically. ${ }^{26}$ There is higher solubilisation capacity and thermodynamic stability in nanoemulsion, long self-life, and fast onset of action. ${ }^{27}$ The quantity and releasing pattern of drug from nano-emulgel can be modified with varying concentration of used ingredients, gelling agent base oil in emulsion. ${ }^{28,29}$ There are two type of nanoemulsion: oil in water $(\mathrm{O} / \mathrm{W})$ and water in oil (W/O), transportation of lipophillic actives into deep part of skin shows better results with $\mathrm{O} / \mathrm{W}$ nanoemulsion. ${ }^{30}$ The drugs having bitter taste that cannot be taste- masked is much preferred to deliver in the form of nanoemulgel via the topical route. ${ }^{31}$ When compared nano-emulgel with nanoemulsion, the drug permeation from nano-emulgel system occurs through both para-cellular and trans-cellular membrane while drug permeation from nanoemulsion occurs through transcellular membranes only across the skin whereas the conventional semi-solid dosage forms exhibited shallow penetration across the $\operatorname{skin}^{32}$ as shown in Figure 1.

Nano-emulgel exhibited better partitioning through percutaneous membrane of drug molecule for required therapeutic activity at the site of action. $^{26,27}$ The system shows high mucoadhesion, thus acts as a drug reservoir for sustained release of drug and improved patient compliance. ${ }^{33}$ Nanoemulgel offers several advantages such as high solubility of drug, better spread ability, biocompatibility, thixotropic behaviour, excellent carriers for lipophilic drugs, non-toxic, non-irritant, and better drug loading as compared to other topical formulations, suitable for sustained and prolonged release of drugs with shorter half-life, improved skin penetration, and better drug deposition, less sticky feeling when compared to conventional semisolid dosage form (creams, ointment etc.). The system is suitable for both local and systemic effects depending upon the site of actions. ${ }^{34,35}$ Several literatures have reported that nano-emulgel system have been found to show auto photo quenching qualities to control phototoxicity when used in photodynamic therapy. ${ }^{36,37}$

The system is also associated with several disadvantages like stickiness problem when applied to skin, drug with larger particle size faces difficulty to cross the skin barriers, low spread ability and stability issues for hydrophilic drug candidates. ${ }^{38}$ With all the benefits, nano-emulgel can be considered as an excellent alternate delivery system for the management of various skin disorders like psoriasis 
to overcome the side-effects of oral route and improved effectiveness of medicines for better patient compliance. ${ }^{33}$ The nano-emulgel based drug delivery is an approach to improve therapeutic profiles and systemic delivery of lipophilic drugs. Various researches have been reported based on nano-emulgel formulation for topical delivery of lipophilic drugs. Some of the latest researches based on the preparation containing vesicles such as nanoemulgel, nanoemulsion and microemulsion are highlighted in Table 1.

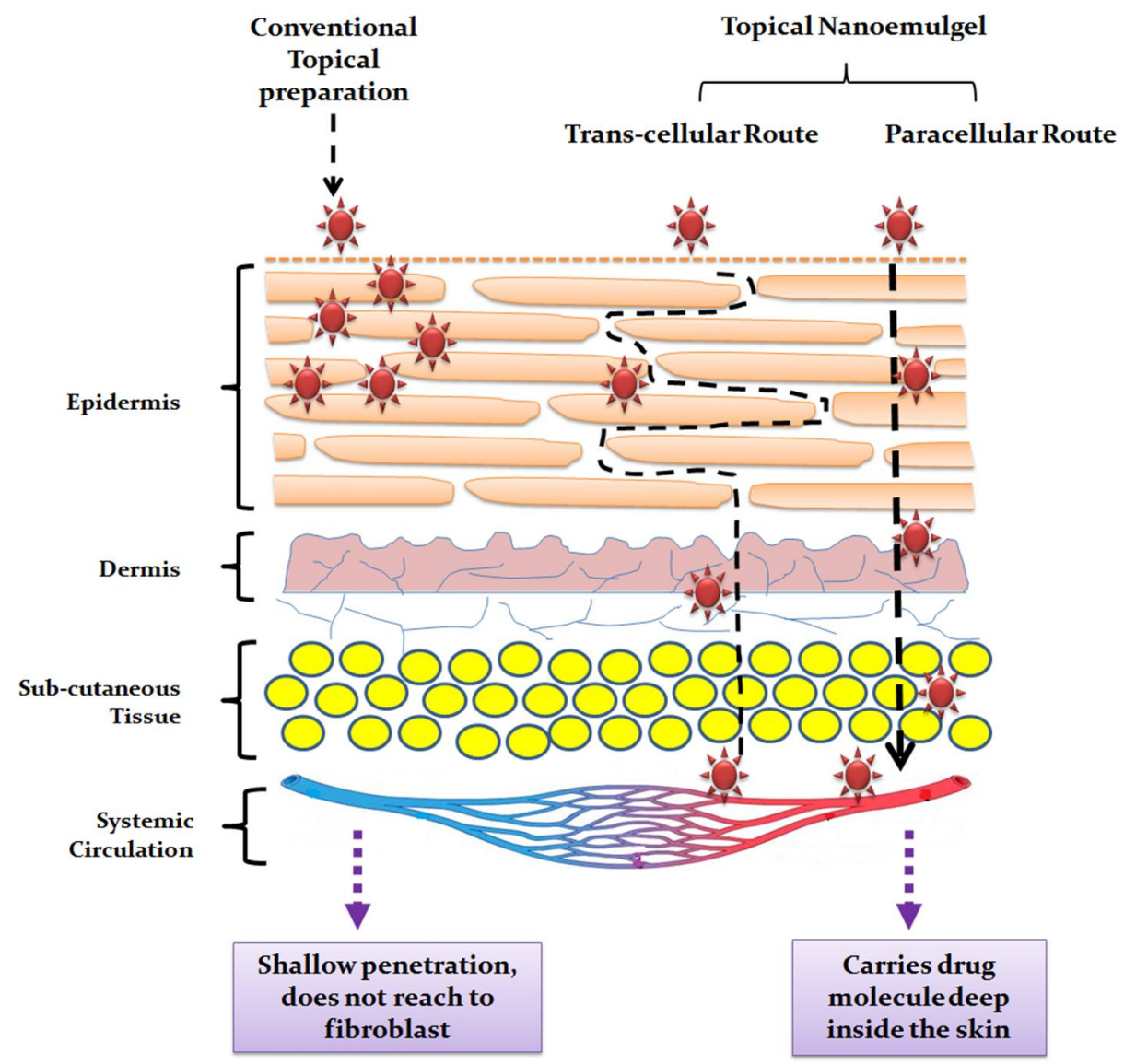

Figure 1. Representation of the permeation patterns of conventional gels and nano-emulgel system across the skin.

\section{FORMULATION CONSIDERATIONS}

The process of nano-emulgel preparation involved three basic steps that include (i) development of nano-emulsion system either by spontaneous emulsification or high pressure homogenization; (ii) hydrogel system separately and (iii) mixing of both the systems together to form nano-emulgel formulation. ${ }^{26}$ There are two methods which are generally used for preparing nanoemulsion namely high-energy and low-energy methods. The former methods include processes like high-pressure homogenization, ultrasound generation or sonication, micro-fluidization and high shear stirring methods whereas the latter methods involves technologies such as spontaneous emulsification, phase inversion, emulsion inversion point etc. ${ }^{69}$ Various excipients along with active pharmaceutical ingredients have been used to make nano-emulgel such as: (i) Oil and lipids: their selection for nanoemulsion preparation directly correlates with the choice of surfactants/cosurfactants. For nanoemulsion preparation, generally long chain triglycerides (LCT), medium chain 
Table 1. Topical nano-emulgel/ nanoemulsion/ preparations for various skin diseases.

\begin{tabular}{|c|c|c|c|c|}
\hline Author/ Year & Drug/System & Oil/ polymer used in system & $\begin{array}{l}\text { Preparation for nano- } \\
\text { emulsion }\end{array}$ & $\begin{array}{c}\text { Reference } \\
\text { number }\end{array}$ \\
\hline Gurjot et al. (2019) & $\begin{array}{l}\text { Mefanamic acid- tocopheryl } \\
\text { polyethylene glycol succinate } \\
\text { nano-emulgel }\end{array}$ & $\begin{array}{l}\text { Capryol, Oleic, Soyabean oil /Tween- } \\
\text { 20,40,60, Span-80, Carbopol (971, } \\
\text { 940), HPMC 5-CPS }\end{array}$ & $\begin{array}{l}\text { Spontaneous Emulsification } \\
\text { Method }\end{array}$ & 39 \\
\hline $\begin{array}{l}\text { Lakshmana et al. } \\
\text { (2017) }\end{array}$ & $\begin{array}{l}\text { Cyclobenzaprine } \\
\text { Hydrochloride nanoemulgel }\end{array}$ & $\begin{array}{l}\text { Castor, Orange, Nutmeg oil / Tween } \\
80, \text { Span } 80, \text { Carbopol } 940\end{array}$ & Emulsification method & 27 \\
\hline $\begin{array}{l}\text { Dhawan et al. } \\
\text { (2014) }\end{array}$ & Piroxicam nanoemulgel & Oleic acid / tween 80, Carbopol 934 & Emulsification method & 40 \\
\hline $\begin{array}{l}\text { Ahmed M. Eid et al. } \\
\text { (2019) }\end{array}$ & $\begin{array}{l}\text { Fusidic acid \& sodium fusidate } \\
\text { nanoemulgel }\end{array}$ & $\begin{array}{l}\text { Pine, Olive, Corn Oil / Tween-20,80, } \\
\text { Span - } 20,80\end{array}$ & $\begin{array}{l}\text { Self- nanoemulsification } \\
\text { technique }\end{array}$ & 41 \\
\hline $\begin{array}{l}\text { Khurana et al. } \\
\text { (2013) }\end{array}$ & Meloxicam Nanoemulsion gel & $\begin{array}{l}\text { Caprylic acid as oil phase / Tween } 80 \text {, } \\
\text { Carbopol } 940\end{array}$ & Emulsification method & 42 \\
\hline Eid et al. (2014) & $\begin{array}{l}\text { Swietenia microphylla } \\
\text { nanoemulgel }\end{array}$ & SM oil/Carbopol 934,940 & $\begin{array}{l}\text { Self-emulsification method } \\
\text { and phase inversion } \\
\text { technique }\end{array}$ & 43 \\
\hline Javed et.al. (2019) & Tea oil nanoemulgel & $\begin{array}{l}\text { Tree tea oil/Tween 20, 80, Carbopol } \\
940 \text {, PEG400 }\end{array}$ & Emulsification method & 44 \\
\hline Mao et al. (2019) & Eprinomectin nanoemulgel & Castor oil/Tween 80, Carbopol 940 & Emulsification method & 45 \\
\hline Dixit et al. (2019) & Anthralin microemulsion gel & Karanj oil/Tween 80, Span 20 & Emulsification method & 46 \\
\hline Mulia.et al. (2018) & Mangosteen nanoemulgel & Coconut oil / Span 80 , Tween 80 & Emulsification method & 47 \\
\hline $\begin{array}{l}\text { Tungadi. et al. } \\
(2020)\end{array}$ & $\begin{array}{l}\text { Snakehead fish powder } \\
\text { nanoemulgel }\end{array}$ & Olive oil / Tween 80, PEG 400 & $\begin{array}{l}\text { Low pressure } \\
\text { homogenization method }\end{array}$ & 48 \\
\hline $\begin{array}{l}\text { Pradum et al. } \\
\text { (2019) }\end{array}$ & Topical Itraconazole nanogel & $\begin{array}{l}\text { Water/ Tween 80, Span 80, Carbopol } \\
940\end{array}$ & Solvent diffusion method & 49 \\
\hline Urmila et al. (2013) & Allyl amine nanoemulgel & Soya oil / Tween 80, Carbopol 934 & $\begin{array}{l}\text { Spontaneous emulsification } \\
\text { method }\end{array}$ & 50 \\
\hline $\begin{array}{l}\text { Subheet } \text { et al. } \\
\text { (2017) }\end{array}$ & $\begin{array}{l}\text { Vitamin E- Tocopheryl } \\
\text { polyethylene glycol succinate } \\
\text { nanoemulsion }\end{array}$ & $\begin{array}{l}\text { Olive oil, Oleic oil / Carbopol } \\
934,940\end{array}$ & High energy method & 51 \\
\hline Pintu et al. (2018) & Curcumin nanoemulgel & Curcumin oil / Tween 80 & Ultrasonication method & 52 \\
\hline $\begin{array}{l}\text { Mustafa et al. } \\
\text { (2019) }\end{array}$ & $\begin{array}{l}\text { Apixaban ultrafine } \\
\text { nanoemulsion }\end{array}$ & $\begin{array}{l}\text { Castor, Olive, Coconut etc / Tween } \\
\text { 20, Tween } 80 \text {, Span } 20 \text {, Span } 80\end{array}$ & $\begin{array}{l}\text { Emulsification method, } \\
\text { aqueous titration method }\end{array}$ & 53 \\
\hline Ghosh. et al. (2013) & Cinnamon oil nanoemulsion & Cinnamon oil / Tween 80 & $\begin{array}{l}\text { Ultrasonic emulsification } \\
\text { method }\end{array}$ & 54 \\
\hline Ahuja. et al. (2008) & Aceclofenac nanoemulsion & Lebrafil as oil phase /Tween 80 & $\begin{array}{l}\text { Spontaneous emulsification } \\
\text { method }\end{array}$ & 55 \\
\hline $\begin{array}{l}\text { Vaiyapuri et al. } \\
\text { (2016) }\end{array}$ & $\begin{array}{l}\text { Essential oil based } \\
\text { nanoemulsion }\end{array}$ & Nigella Sativa L oil /Polysorbate 80 & $\begin{array}{l}\text { Ultrasonic emulsification } \\
\text { method }\end{array}$ & 56 \\
\hline Vaida et al. (2015) & Resveratrol microemulsion & Oleic, Olive oil / PEG 8 & Oil titration method & 57 \\
\hline Vidya et.al. (2012) & $\begin{array}{l}\text { Bifonazole topical } \\
\text { microemulgel }\end{array}$ & Oleic acid as oil / Tween 80 & Emulsification method & 58 \\
\hline Altug.et al. (2014) & Naproxen microemulsion & Isopropyl myristate as oil / Span 80 & Emulsification method & 59 \\
\hline Vishal et al. (2018) & Ramipril microemulsion & Orange oil / Tween 80 & Water titration method & 60 \\
\hline Hemal et. al. (2012) & Cilnidipine microemulsion & Tocotrienol as oil / Tween 20 & Titration method & 61 \\
\hline Kohli et al. (2007) & Terbinafine microemulsion & Oleic acid as oil / Labrasol S & $\begin{array}{l}\text { Spontaneous emulsification } \\
\text { method }\end{array}$ & 62 \\
\hline Aparna et al. (2014) & $\begin{array}{l}\text { Satranidazole micro-emulsion } \\
\text { gel }\end{array}$ & $\begin{array}{l}\text { Oleic acid, Olive as oil / Tween } 80 \text {, } \\
\text { Carbopol } 940\end{array}$ & $\begin{array}{l}\text { Cosurfactant titration } \\
\text { method }\end{array}$ & 63 \\
\hline $\begin{array}{l}\text { Mohammad et al. } \\
\text { (2012) }\end{array}$ & $\begin{array}{l}\text { Turmeric oil topical } \\
\text { nanoemulsion }\end{array}$ & $\begin{array}{l}\text { Turmeric oil / Tween 80, Carbopol } \\
940\end{array}$ & $\begin{array}{l}\text { Spontaneous emulsification } \\
\text { method }\end{array}$ & 64 \\
\hline Rajitha et al. (2019) & $\begin{array}{l}\text { Chaulmoogra oil-methotrexate } \\
\text { nanoemulsion }\end{array}$ & Chaulmoogra oil / Tween 80 & Emulsification method & 65 \\
\hline Jain et al. (2011) & $\begin{array}{l}\text { Methoxsalen topical micro- } \\
\text { emulgel }\end{array}$ & $\begin{array}{l}\text { Ethyl oleate as oil phase / Tween } 80 \text {, } \\
\text { Carbopol } 934\end{array}$ & Emulsification method & 66 \\
\hline Trivedi et al. (2018) & $\begin{array}{l}\text { Clobetasol propionate and } \\
\text { salicylic acid topical } \\
\text { microemulsion }\end{array}$ & $\begin{array}{l}\text { Oleic acid as oil phase/ Tween } 20 \text {, } \\
\text { Tween } 80 \text {, PEG } 400\end{array}$ & Water titration method & 67 \\
\hline $\begin{array}{l}\text { Tejinder } \text { et al. } \\
(2013)\end{array}$ & Babchi oil topical emulgel & $\begin{array}{l}\text { Babchi oil / Capryol 90, Tween - 20, } \\
80 \text { Span - 20, } 80\end{array}$ & Emulsification method & 68 \\
\hline
\end{tabular}


triglyceride (MCT) and short chain triglycerides (SCT) are selected such as triacetin, trybutyrin etc. $^{70,71}$ Apart from these, various vegetable oils (castor oil, olive oil, coconut oil, almond oil, sesame oil, soyabean oil, etc) from plant sources approved for topical delivery are used in the preparation of nano-emulgel. ${ }^{72-76}$ Other than this, various fatty acid and alcohol (Stearyl alcohol, cetyl alcohol etc. ${ }^{72}$, fatty acid ester and glycerol (butyric acid derivatives, glycerol triacetate etc. ${ }^{77}$ have been used as oil phase in preparation of nanoemulsion for nano-emulgel. (ii) Vehicles: nanoemulsion is commonly prepared in distilled water and solvents with high polarity. (iii) Gelling agent: They are used to prepare hydrogel and gel-matrix, e.g. agar gum, guar gum, xanthan gum, HPMC, tragacanth etc. (iv) Permeation enhancers are added in preparation to interact with the skin constituent to produce reversible temporary increase in permeability to skin layer, eg; linoleic acid, oleic acid, lecithin etc. (v) Surfactants/co-surfactants: stabilizes the formulation and helps in solubilising the drugs, eg; Acrysol, Labrasol, Tween 80, Tween 20 , Span 80 , stearic acid, etc. ${ }^{38}$

After preparation, the nano-emulgel formulations are generally evaluated for various in-vitro and invivo parameters including determination of drug content, particle/vesicle size, grittiness, $\mathrm{pH}$, spreadability, viscosity measurement and rheological behaviour, zeta potential, poly-dispersity index (PDI), mucoadhesive property, ex-vivo drug permeation studies, in-vivo studies, skin irritancy study and stability studies. These parameters may influence the drug delivery and system's overall performance. ${ }^{78-89}$

\section{Topical applications of nanoemulgel in managing psoriasis.}

Psoriasis can be treated by various medications whether by single dose or in combination. About $75 \%$ of patients having moderate psoriasis are treated by topical medications. ${ }^{90}$ The most common etiological factor is stress. ${ }^{3}$ Certain factor like mental strain, skin damage, systemic infections, chronic disorders like Crohn's disease and intestinal upsets can affect the conditions of psoriasis. ${ }^{91}$ Various drug delivery systems have been developed and reported for the treatment of psoriasis such as oral drug delivery, systemic drug delivery and topical drug delivery including creams, ointment, shampoo and gel preparations. $^{92-95}$ Several conventional and approved medicines are available for the treatment of psoriasis based on its severity. The treatment include corticosteroids, vitamin D, retinoids (topical), combination of methotrexate with ultraviolet B (UVB) phototherapy (first line therapy), acetratin, apremilast (non-biologics, first line therapy), and methotrexate with biologics (Infliximab and Efalizumab monoclonal antibodies) and UVB with biologics (second line therapy). For light therapy exposure of light in short wavelength is called UVB. Side effects of light therapy include skin damage, and may have chance of skin cancer. Systemic treatment may be given through oral and parental route in moderate to severe psoriasis. ${ }^{5,96,97}$

The major drawback of wide range of antipsoriatic drugs used via the topical route includes side effects like low permeability through transcutaneous membrane resulting low bioavailability, which makes it clinically less important and emerges the need to develop advanced topical drug delivery systems for psoriasis. Generally, topical preparation like gels, creams, ointment, and lotions can be given as alone or in combination of drugs to treat mild to moderate psoriasis. ${ }^{98}$ Some of the marketed topical preparations are given in Table 2.

Nano-emulgel as effective carriers for antipsoriatic agents. Nano-emulgel delivery system for anti-psoriatic agents has great potential for better clinical effect of drug candidates in psoriasis as the system exhibits deep percutaneous permeation across the membranes. Drug delivery using nano-emulgel system is used for improving therapeutic action of lipophilic drug and systemic delivery. ${ }^{32}$ Basically, nano-emulgel are made up of $\mathrm{o} / \mathrm{w}$ nanoemulsion admixture with gelling agent. The system offers 
several advantages like patient compliance, increased stability with reduced surface tension, non-irritating nature, non-toxicity. ${ }^{99,100}$ Several literatures revealed the pharmacokinetic studies of the nano-emulgel system in topical delivery suggesting a variety of benefits such as enhanced permeation of drug through the skin, reduces dosing frequency, sustained release effect for desired duration, depot release of drug at site of action, avoids hepatic first pass metabolism, improved stability, and reduced dose required and hence lesser dose related toxicity. In case of psoriasis, nano-emulgel formulation exhibits deep penetration across the stratum corneum at the site of action for long time resulting in better treatment approach along with reduced dose and dosing frequency of actives and hence strongly suggests the topical nano-emulgel formulation containing anti-psoriatic agent as a suitable alternate delivery system by overcoming the sufferings of oral administration of drugs causing side effects and also better patient compliance in managing psoriasis..$^{101,102}$ Some of the marketed products based on various nanocarriers based delivery systems indicated in different skin conditions are shown in Table 3.

Table 2. Commercially available topical anti-psoriatic preparations.

\begin{tabular}{llll}
\hline $\begin{array}{l}\text { Marketed } \\
\text { products }\end{array}$ & Drug used & Company name & Major side effects \\
\hline Elocon & Mometasone Furoate & MSD & $\begin{array}{l}\text { Allergic skin reactions } \\
\text { Loss of skin colour, Acne } \\
\text { Dovonex }\end{array}$ \\
Taclonex & Calcipotriene & Leo Pharma & Hypercalcemia, Local irritation \\
& Calcipotriene Betamethasone & Leo pharma & Erythema, Stinging sensation \\
Tazorac & Tazarotene & & Dry skin \\
Temovate & Clobetasol propionate & Allergen Pharmaceuticals & Burning and irritation \\
& & PharmaDerm & Thinning and cracking of skin, burning, \\
Diprolene & Betamethasone dipropionate & Schering & Blisters, itching and peeling of skin \\
Diprosalic & Betamethasone dipropionate and & Merck Sharp and Dohme & Dermatitis \\
& Salicylic acid & Limited & Allergic skin reactions \\
\hline
\end{tabular}

Table 3. Emulsion-based and nanocarrier-based gels preparations available in the market.

\begin{tabular}{llll}
\hline Marketed products & Indications & Carrier used & Company name \\
\hline Voltaren & Inflammation /pain & Emulgel & Novartis pharma \\
Miconaz-H & Vaginal infection & Emulgel & Medical Union Pharmaceutical \\
Diclomax & Pain & Emulgel & Torrent pharma \\
Zyclin & Acne & Nanogel & ZydusCadila \\
Adalene & Acne & Nanogel & Cam- Camilin Ltd. \\
Oxalgin & Gout, migrane & Nanogel & ZydusCadila \\
Eye perfector gel & Dark circle & Liposome & Avon solution \\
Nanofast gel & Gout, migrane & Nanoemulsion & Pharmed Ltd. \\
Biogelmicroemulsion & Dry skin & Microemulsion & BioOne \\
Nano cream & Dark circle & Nanoemulsion & Collonil \\
Anti-age response cream & Skin aging & Noisome & St. Botanica \\
Vital Nanoemulsion A-VC & Dry skin & Nanoemulsion & Marie Louise \\
Lip Tender & Dry lips & Nanosphere & LHB \\
Ravitalift & Anti-aging & Liposome & L'Oreal \\
\hline
\end{tabular}


Future scope of nano-emulgel in topical delivery. Based on various literature discussed in this review, it is suggested that nano-emulgel delivery system has emerged as one of the best and smart alternatives among various novel drug delivery system for topical use. The nano-emulgel delivery system is very effective for poor aqueous soluble drug candidates which have been abolished from development processes due to limited clinical efficacy. The system is believed to enhance the pharmacodynamic and pharmacokinetic properties of drugs having poor bioavailability resulting better patient compliance. Many of the lipophilic drugs belonging to different categories have been incorporated in nano-emulgel system suggesting increased therapeutic profiles in respect to better penetration in skin layer, non-greasy nature, nontoxic, avoid hepatic first pass metabolism and safety. The developed nano-emulgel has been tested against many acute and chronic diseases like inflammatory disorder, cardiovascular disease, fungal infections and alopecia. With all benefits, it could be inferred that nano-emulgel system can be a better and potential drug delivery tool for the treatment of psoriasis topically to achieve better treatment strategies and more patient compliance in near future in patients who suffer with oral medications.

\section{CONCLUSIONS}

The nano-emulgel drug delivery system is aimed to develop with improved therapeutic profiles as well as systemic availability of various lipophilic drugs belonging to BCS class II and IV. Several research reports demonstrated the increase drug profiles when incorporated in nano-emulgel formulations. The selection of appropriate vehicles, surfactants/cosurfactants and methods of fabrication has huge impact on the stability and biological behavior of the developed nanocarrier systems such as nano-emulgel, nanoemulsion, microemulsions, liposomes, etc. The choice of surfactant is of important concern as the increased concentration of surfactants may cause mild to severe toxicity. Hence, it can be concluded that lipoidal emulsion-based nanocarrier system is a safe and effective alternative approach to conventional delivery system for topical applications in the management of variety of psoriasis and other skin disorders.

\section{ACKNOWLEDGMENT}

Authors are thankful to I.T.S College of Pharmacy, Murad Nagar, Ghaziabad, Uttar Pradesh (201206) India, for providing us the platform and infrastructure for preparing this manuscript.

\section{COMPETING INTEREST}

Authors declare no competing interest.

\section{REFERENCES}

1. Rahman, B.S., Anwar, F., Al-Abbasi, F.A. and Kumar, V. 2016. In: Nanotechnology based nano bullets in antipsoriatic drug delivery: State of the Art. Nanoscience in Dermatology. Elsevier, pp. 157-66.

2. Rendon, A. and Schakel, K. 2019. Psoriasis pathogenesis and treatment. Int. J. Mol. Sci. 20, 1475.

3. Dutta, S., Chawla, S. and Kumar, S. 2018. Psoriasis: a review of existing therapies and recent advances in treatment. $J$. Rational. Pharmacother. Res. 4, 12-23.

4. Kimmel, G.W. and Lebwohl, M. 2018. In: Psoriasis: Overview and Diagnosis. (Bhutani T., Liao W., Nakamura M. Eds). Updates in Clinical Dermatology, Springer, Cham, pp. 1-16.

5. Ayala, F. 2007. Clinical presentation of psoriasis. Reumatismo. 59, 40-45.

6. Langley, R.G., Krueger, G.G. and Griffiths, C.E. 2005. Psoriasis: epidemiology, clinical features, and quality of life. Ann. Rheum. Dis. 64, 18-23.

7. Lande, R., Botti, E., Jandus, C., Dojcinovic, D., Fanelli, G., Conrad, C., Chamilos, G., Feldmeyer, L., Marinari, B., Chon, S., Vence, L., Riccieri, V., Guillaume, P., Navarini, A.A., Romero, P., Costanzo, A., Piccolella, E., Gilliet, M. and Frasca, L. 2014. The antimicrobial peptide LL37 is a T-cell autoantigen in psoriasis. Nat. Commun. 3, 5621.

8. Arakawa, A., Siewert, K., Stöhr, J., Besgen, P., Kim, S.M., Ruhl, G., Nickel, J., Vollmer, S., Thomas, P., Krebs, S., Pinkert, S., Spannagl, M., Held, K., Kammerbauer, C., Besch, R., Dornmair, K. and Prinz, J.C. 2015. Melanocyte antigen triggers autoimmunity in human psoriasis. J. Exp. Med. 212, 2203-2212. 
9. Sarac, G., Koca, T.T. and Baglan, T. 2016. A brief summary of clinical types of psoriasis. North. Clin. Istanbul. 3, 79-82.

10. Wolff, K., Goldsmith, L., Katz, S., Gilchrest, B., Paller, AS., and Leffell, D. 2011. In: Fitzpatrick's Dermatology in General Medicine, Dermatology Pediatrics, McGraw-Hill, $8^{\text {th }}$ Ed., pp. 169-194.

11. Braun-Falco, O., Plewig, G., Wolff, H.H., Winkelmann, R.K. 2000. In: Dermatology. Berlin: Springer-Verlag, $2^{\text {nd }} E d .$, pp. 585-607.

12. Bolognia, J.L. and Jorizzo, J.L. 2003. In: Papulosquamous and Eczematous Dermatoses: Psoriasis. Edinburg: Mosby, $2^{\text {nd }}$ Ed., pp.125-149.

13. Yanagisawa, H., Richardson, J.A., Taurog, J.D. and Hammer, R.E. 1995. Characterization of psoriasiform and alopecic skin lesions in HLA-B27 transgenic rats. Am. J. Pathol. 147, 955964.

14. Xia, Y.P., Li, B., Hylton, D., Detmar, M., Yancopoulos, G.D. and Rudge, J.S. 2003. Transgenic delivery of VEGF to mouse skin leads to an inflammatory condition resembling human psoriasis. Blood. 102, 161-168.

15. Zeigler, M., Chi, Y., Tumas, D.B., Bodary, S., Tang, H. and Varani, J. 2001. Anti-CD11a ameliorates disease in the human psoriatic skin-SCID mouse transplant model: comparison of antibody to CD11a with cyclosporin A and clobetasol propionate. Lab. Invest. 81, 1253-1261.

16. Mrinalini, C.D., Mangesh, R.B. and Sneha, A.L. 2017. Formulation and evaluation of herbal gel for treatment of psoriasis. World J. Pharm. Pharm. Sci. 6, 1199-1210.

17. Kshirsagar, N.A. 2000. Drug delivery systems. Ind. J. Pharmacol. 32, S54-S61.

18. Patil, P., Datir, S. and Saudagar, R. 2019. A review on topical gels as drug delivery system. JDDT. 9, 989-994.

19. Prausnitz, M.R. and Langer, R. 2008. Transdermal drug delivery. Nat. Biotechnol. 26, 1261-1268.

20. Jain, A., Deveda, P., Vyas, N., Chauhan, J., Hemant, K. and Sanjay, J. 2011. Gellified emulsion for sustain delivery of itraconazole for topical fungal diseases. IJPRD. 2, 18-25.

21. Bruton, L., Keith, P., Blumenthal, D. and Buxton, Z. 2008. In: Goodman \& Gillman's Manual of Pharmacology and Therapeutics, McGraw's Hill, pp. 1086-1094.

22. Ahmed, M. and Ali, M. 2016. Semisolid dosage form: topical gel formulation a review. World J. P'ceutical Rese 5, 12561268.

23. Tamjidi, F., Nasirpour, A., Varshosaz, J. and Shahedi, M. 2013. Nanostructured lipid carriers (NLC): a potential delivery system for bioactive food molecules. Innov. Food Sci. Emerg. Technol. 19, 29-43.

24. Rahman, M., Kumar, V., Beg, S., Sharma, G., Katare, O.P. and Anwar, F. 2016. Emergence of liposome as targeted magic bullet for inflammatory disorders: current state of the art. Artif. Cells. Nanomed. Biotechnol. 44, 1597-608.
25. Algahtani, M.S. Ahmad, M.Z. and Ahmad, J. 2020. Nanoemulsion loaded polymeric hydrogel for topical delivery of curcumin in psoriasis. J. Drug. Deliv. Sci. Technol. 59, 2020: 101847.

26. Basera, K., Bhatt, G., Kothiyal, P. and Gupta, P. 2015. Nanoemulgel: a novel formulation approach for topical delivery of hydrophobic drugs. World. J. Pharm. Pharm. Sci. 4, 1871-1886.

27. Lakshman Prabhu, S., Sharvanan, S.P., Aravindan, S., Bhuvaneswari, A. and Manikandan, V. 2017. Nanoemulgel for transdermal delivery of cyclobenzaprine hydrochloride. NAPDD. 1, 555-575.

28. Mohamed, M.I. 2004. Optimization of chlorphenesin emulgel formulation. AAPS J. 6, e26.

29. Rahil, M., Bhura G., Khushboo, A., Bhagat, and Samir, K.S. 2015. Formulation and evaluation of topical nanoemulgel of adapalene. World. J. Pharm. Sci. 3, 1013-1024.

30. Taglietti, M., Hawkins, C.N. and Rao, J. 2008. Novel topical drug delivery systems and their potential use in acne vulgaris. Skin. Therapy. Lett. 13, 6-8.

31. Sutradhar, K.B., and Mohammad, L.A. 2013. Nanoemulsion: increasing possibilities in drug delivery. Eur. J. Nanomed. 5, 97-110.

32. Sengupta, P. and Chatterjee, B. 2017. Potential and future scope of nanoemulgel formulation for topical delivery of lipophilic drugs. Int. J. Pharm. 526, 353-365.

33. Ajazuddin Alexander, A., Khichariya, A., Gupta, S., Patel, R.J., Giri, T.K. and Tripathi, D.K. 2013. Recent expansions in an emergent novel drug delivery technology: emulgel. $J$. Control. Release. 171, 122-32.

34. Barry, B.W. 2004. Breaching the skin's barrier to drugs. Nat. Biotechnol. 22, 165-167.

35. Paudel, K.S., Milewski, M., Swadley, C.L., Brogden, N.K., Ghosh, P. and Stinchcomb, A.L. 2010. Challenges and opportunities in dermal/transdermal delivery. Ther. Deliv. 1, 109-131.

36. Li, F., Bae, B.C. and Na, K. 2010. Acetylated hyaluronic acid/photosensitizer conjugate for the preparation of nanogels with controllable phototoxicity: synthesis, characterization, auto-photoquenching properties, and in vitro phototoxicity against HeLa cells. Bioconjug. Chem. 21, 1312-1320.

37. Arianto, A., Lie, D.Y., Sumaiyah, S. and Bangun, H. 2020. Preparation and evaluation of nanoemulgels containing a combination of grape seed oil and anisotriazine as sunscreen. Open Access Maced. J. Med. Sci. 8, 994-999.

38. Malay, N.J., Chandresh, P.P. and Bhupendra, G.P. 2018. Nanoemulgel approach for topical gel formulation. RRHOAJ. 2, 18-21.

39. Gurjot, K. 2019. TPGS loaded topical nanoemulgel of mefenamic acid for the treatment of rheumatoid arthritis. IJPPR. Human. 15, 64-107. 
40. Dhawan, B., Aggarwal, G. and Harikumar, S. 2014. Enhanced transdermal permeability of piroxicam through novel nanoemulgel formulation. Int. J. Pharm. Investig. 4, 65-76.

41. Eid, A.M., Istateyeh, I., Salhi, N. and Istateyeh, T. 2019. Antibacterial activity of fusidic acid and sodium fusidate nanoparticles incorporated in pine oil nanoemulgel. Int. J. Nanomed. 14, 9411-9421.

42. Khurana, S., Jain, N.K. and Bedi, P.M. 2013. Nanoemulsion based gel for transdermal delivery of meloxicam: physicochemical, mechanistic investigation. Life. Sci. 92, 383-92.

43. Ahmad, M.E., El-Enshasy, H.A., Ramlan, A. and Nagib, A.E. 2014. Preparation, characterization and anti-inflammatory activity of Swietenia macrophylla nanoemulgel. J. Nanomed. Nanotechnol. 5, 190.

44. Ahmad, J., Gautam, A., Komath, S., Bano, M., Garg, A. and Jain, K. 2019. Topical nano-emulgel for skin disorders: formulation approach and characterization. Recent. Pat. Antiinfect. Drug. Discov. 14, 36-48.

45. Mao, Y., Chen, X., Xu, B., Shen, Y., Ye, Z., Chaurasiya, B., Liu, L., Li, Y., Xing, X. and Chen, D. 2019. Eprinomectin nanoemulgel for transdermal delivery against endoparasites and ectoparasites: preparation, in vitro and in vivo evaluation. Drug. Deliv. 26, 1104-1114.

46. Dixit, G.R., Shende, A.B. 2018. Formulation and evaluation of anthralin microemulsion gel using karanj oil. IJPSR. 5, 2041-2050.

47. Kamarza, M., Rosalia, M.A., Ramadhan, and Krisanti, E.A. 2018. Formulation and characterization of nanoemulgel mangosteen extract in virgin coconut oil for topical formulation. MATEC. Web. Conf. 156, 01013.

48. Robert, T. and Ekawaty, P. 2017. Evaluation of physical stability and antibacterial properties of snakehead fish (Ophiocephalus Striatus) cream containing immunoglobulin. Int. J. Chemtech. Res. 10, 200-206.

49. Wadile, K.A., Ige, P.P. and Sonawane, R.O. 2019. Preparation of itraconazole nanoparticles and its topical nanogel: Physicochemical properties and stability studies. Int. J. Pharm. Sci. Dev. Res. 5, 001-008.

50. Syamala, U. 2013. Development \& optimization of allyl amine antifungal nanoemulgel using 23 factorial design for the treatment of Tinea pedis. Eur. Sci. J. 4, 597-605.

51. Kaur, L., Subheet, K.J. and Singh, K. 2017. Vitamin E TPGS based nanogel for skin targeting of high molecular weight anti-fungal drug: development, in vitro and in vivo assessment. RSC Advances. 5, 53671-53686.

52. Pintu, K.D., Manami, D. and Soumen, R. 2018. Fabrication and characterization of curcumin nanoemulgel to overcome the challenges in ophthalmic drug delivery system. Saudi $J$. Med. Pharm. Sci. 4, 109-118.
53. Mustafa, R.A., Rajab, N.A. 2020. Apixaban ultrafine $\mathrm{o} / \mathrm{w}$ nano emulsion transdermal drug delivery system: formulation, in vitro and ex vivo characterization. Sys. Rev. Pharm. 11, 82-94.

54. Ghosh, V., Saranya, S., Mukherjee, A. and Chandrasekaran, N. 2013. Cinnamon oil nanoemulsion formulation by ultrasonic emulsification: investigation of its bactericidal activity. J. Nanosci. Nanotechnol. 13, 114-122.

55. Shakeel, F., Baboota, S., Ahuja, A., Ali, J., Aqil, M. and Shafiq. S. 2007. Nanoemulsions as vehicles for transdermal delivery of aceclofenac. AAPS Pharm. Sci. Tech. 14, E104.

56. Periasamy, V.S., Athinarayanan, J. and Alshatwi, A.A. 2016. Anticancer activity of an ultrasonic nanoemulsion formulation of Nigella sativa L. essential oil on human breast cancer cells. Ultrason. Sonochem. 31, 449-455.

57. Juskaite, V., Ramanauskienè, K. and Briedis, V. 2015. Design and formulation of optimized microemulsions for dermal delivery of resveratrol. Evid. Based. Complement. Alternat. Med. 540916.

58. Sabale, V., Vora, S. 2012. Formulation and evaluation of microemulsion-based hydrogel for topical delivery. Int. J. Pharm. Investig. 2, 140-149.

59. UstündagOkur, N., Yavaşoglu, A. and Karasulu, H.Y. 2014. Preparation and evaluation of microemulsion formulations of naproxen for dermal delivery. Chem. Pharm. Bull. (Tokyo) 62, 135-143.

60. Vishal, Y., Prakash, J., Kishor, K. and Shailaja, D. 2018. Preparation and evaluation of microemulsion containing antihypertensive drug. Int. J. Appl. Pharm. 10, 138-146.

61. Tandel, H., Raval, K., Nayani, A. and Upadhay, M. 2012. Preparation and evaluation of cilnidipine microemulsion. $J$. Pharm. Bioallied Sci. 4, S114-S115.

62. Baboota, S., Al-Azaki, A., Kohli, K., Ali, J., Dixit, N. and Shakeel, F. 2007. Development and evaluation of a microemulsion formulation for transdermal delivery of terbinafine. PDA J. Pharm. Sci. Technol. 61, 276-85.

63. Swaroopa, A., Aparna, C. and Srinivas, P. 2014. Formulation, evaluation and characterization of periodontal microemulsion gel. IJPSDR. 6, 20-25.

64. Ali, M.S., Alam, M.S., Imam, F.I. and Siddiqui, M.R. 2012. Topical nanoemulsion of turmeric oil for psoriasis: characterization, ex vivo and in vivo assessment. Int. J. Drug Deliv. 4, 184-197.

65. Rajitha, P., Shammika, P., Aiswarya, S., Gopikisan, A., Jayakumar, R. and Sabitha, M. 2019. Chaulmoogra oil based methotrexate loaded topical nanoemulsion for the treatment of psoriasis. J. Drug. Deliv. Sci. Technol. 49, 463-476.

66. Behera, J., Keservani, R.K., Yadav, A., Tripathi, M. and Chadoker, A. 2010. Methoxsalen loaded chitosan coated microemulsion for effective treatment of psoriasis. Int. J. Drug Deliv. 2, 159-167. 
67. Trivedi, K., Shaikh, N. and Ravikumar, P. 2018. Development of novel microemulsion based topical formulation of clobetasol propionate and salicylic acid for the treatment of psoriasis. Int. Res. J. Pharm. 9, 1-7.

68. Marwaha T.K. 2013. Formulation, design, evaluation of herbal anti-psoriatic emulgel. J. Pharm. Sci. Innov. 2, 30-42.

69. Kumar, A., Subhabrata, R., Mahfoozur, R., Md. Adil, S., Rudranil, B. and Rammohan, B. 2019. Nano-emulgel: emerging as a smarter topical lipidic emulsion-based nanocarrier for skin healthcare applications. Recent Pat. Antiinfect. Drug Discov. 14, 16-35.

70. Bandyopadhyay, S., Katare, O.P. and Singh, B. 2012. Optimized self-nano-emulsifying systems of ezetimibe with enhanced bioavailability potential using long chain and medium chain triglycerides. Colloids Surf. B. Biointerfaces. 1, 50-61.

71. Singh, Y., Meher, J.G., Raval, K., Khan, F.A., Chaurasia, M., Jain, N.K. and Chourasia, M.K. 2017. Nanoemulsion: concepts, development and applications in drug delivery. $J$. Control. Rel. 252, 28-49.

72. Pawar, K.R. and Babu, R.J. 2014. Lipid materials for topical and transdermal delivery of nanoemulsions. Crit. Rev. Ther. Drug. Carrier. Syst. 31, 429-458.

73. Nastiti, C.M.R.R., Ponto, T., Abd, E., Grice, J.E., Benson, H.A.E. and Roberts, M.S. 2017. Topical nano and microemulsions for skin delivery. Pharmaceutics. 9, 37.

74. Lee, S.Y., Pung, Y.Y., Khor, B.K., Kong, W.E., Tan, C.T., Teo, S.Y. 2016. Lipid-based delivery system for topical phenytoin. J. Appl. Pharm. Sci. 6, 14-20.

75. Dhawan, B., Aggarwal, G. and Harikumar, S. 2014. Enhanced transdermal permeability of piroxicam through novel nanoemulgel formulation. Int. J. Pharm. Investig. 4, 65-76.

76. Bajerski, L., Michels, L.R., Colome, L.M., Bender, E.A., Freddo, R.J., Bruxel, F. and Haas, S.E. 2016. The use of Brazilian vegetable oils in nanoemulsions: an update on preparation and biological applications. Braz. J. Pharm. Sci. 52, 347-63.

77. Lopes, L.B., VanDeWall, H., Li, H.T., Venugopal, V., Li, H.K., Naydin, S., Hosmer, J., Levendusky, M., Zheng, H., Bentley, M.V., Levin, R. and Hass, M.A. 2010. Topical delivery of lycopene using microemulsions: enhanced skin penetration and tissue antioxidant activity. J. Pharm. Sci. 99, 1346-57.

78. Thorat, S.P. and Rane, S.I. 2010. Formulation and in vitro evaluation of lecithin (soya and egg) based aceclofenac organogels. J. Pharm. Res. 3, 1438-1441.

79. Patel, H.K. and Shah D.P. 2018. A review on micro emulsion based gel: an innovative approach for topical delivery of hydrophobic drug. World J. Pharm. Res. 7, 344-349.
80. Tamjidi, F., Ali, N., Jaleh, V. and Mohammad, S. 2013. Nanostructured lipid carriers (NLC): a potential delivery system for bioactive food molecules. Innov. Food. Sci. Emerg. Technol. 19, 29-43.

81. Lakshmi, P. and Kumar, G.A. 2010. Nanosuspension technology: a review. Int. J. Pharm. Pharm. Sci. 2, 35-40.

82. Silva, H.D., Cerqueira, M.A., Vicente, A.A. 2012. Nanoemulsions for food applications: development and characterization. Food. Bioprocess. Technol. 5, 854-867.

83. Horne, D.S. 1995. In: Light scattering studies of colloid stability and gelation. New physicochemical techniques for the characterization of complex food systems. Blackie Academic \& Professional, London, pp. 240-67.

84. Pund, S., Rasve, G. and Borade, G. 2013. Ex vivo permeation characteristics of venlafaxine through sheep nasal mucosa. Eur. J. Pharm. Sci. 48, 195-201.

85. Majithiya, R.J., Ghosh, P.K., Umrethia, M.L. and Murthy, R.S. 2006. Thermoreversible-mucoadhesive gel for nasal delivery of sumatriptan. AAPS Pharm. Sci. Tech. 7, 67.

86. Roa, K.M., Gnanaprakash, K., Badrinath, A.V., Chetty, C.M. and Alagusundaram, M. 2010. Preparation and evaluation of flurbiprofen gel; mucilage of Cocculus hirsutus leaf powder as gel base. Int. J. Pharm. Tech. Res. 2, 1578-1583.

87. Shakeel, F, Ramadan, W., Gargum, H.M. and Singh, R. 2010. Preparation and in vivo evaluation of indomethacin loaded true nanoemulsions. Sci. Pharm. 78, 47-56.

88. Kayes B 1999. In: Dispersed system: Pharmaceutics the Science of Dosage form design (M.E Aulton, Ed), Churchill Livingstone, Edinburgh; $1^{\text {st }}$ Ed, pp. 81-118.

89. Barea, M.J., Jenkins, M.J., Gaber, M.H., Bridson, R.H. 2010. Evaluation of liposomes coated with a $\mathrm{pH}$ responsive polymer. Int. J. Pharm. 15, 89-94.

90. Sarafian, G., Afshar, M., Mansouri, P., Asgarpanah, J., Raoufinejad, K. and Rajabi, M. 2015. Topical turmeric microemulgel in the management of plaque psoriasis; a clinical evaluation. Iran. J. Pharm. Res. 14, 865-876.

91. Pathan, A.K., Rahul, T. and Rukhsana, A.R. 2014. Formulation development and evaluation of silymarin gel in psoriasis treatment. JIPBS. 1, 21-26.

92. Sonia, T. and Tinku, S. 2015. Formulation and evaluation of topical gel containing azithromycin and prednisolone for treating psoriasis. IJPRAS. 4, 45-58.

93. Danilenko, D.M. 2008. Review paper: preclinical models of psoriasis. Vet. Pathol. 45, 563-75.

94. Siddiqui, K., Stein Gold, L., and Gill, J. 2016. The efficacy, safety, and tolerability of ivermectin compared with current topical treatments for the inflammatory lesions of rosacea: a network meta-analysis. Springerplus, 5, 1151.

95. Kircik, L.H. and Kumar, S. 2010. Scalp psoriasis. J. Drugs. Dermatol. 9, s101-5. 
96. Menter, A., Korman, N.J., Elmets, C.A., Feldman, S.R., Gelfand, J.M., Gordon, K.B., Gottlieb, A., Koo, J.Y., Lebwohl, M., Leonardi, C.L., Lim, H.W., Van Voorhees, A.S., Beutner, K.R., Ryan, C. and Bhushan, R. 2011. Guidelines of care for the management of psoriasis and psoriatic arthritis: section 6. Guidelines of care for the treatment of psoriasis and psoriatic arthritis: case-based presentations and evidence-based conclusions. J. Am. Acad. Dermatol. 65, 137-74.

97. Mason, A.R., Mason, J., Cork, M., Dooley, G. and Edwards, G. 2009. Topical treatments for chronic plaque psoriasis. Cochrane Database Syst. Rev. 15, CD005028.

98. Adam, T., Roz, J.A., Paul, W.G. and Suja, E.G. 2010. Current \& potential new therapies for psoriasis. Pharm. J. 284, 560-561.

99. Choudhury, H., Gorain, B., Pandey, M., Chatterjee, L.A., Sengupta, P., Das, A., Molugulu, N. and Kesharwani, P. 2017. Recent update on nanoemulgel as topical drug delivery System. J. Pharm. Sci. 106, 1736-1751.
100. Boon, N., Clledge, N., Wlker, B. and Huner, J. 1995. In: Davidson's Principle and Practice of Medicine. Churchil Livingstone. Edinburgh. $23^{\text {rd }}$ ed, pp. 948-952.

101. Alam M.S., Ali M.S., Alam, N., Alam, M.I., Anwer, T., Imam, F., Ali, M.D., Siddiqui, M.R. and Shamim, M. 2012. Design and characterization of nanostructure topical gel of betamethasone dipropionate for psoriasis. J. App. Pharm. Sci. 2, 148-158.

102. Pund, S., Pawar, S., Gangurde, S. and Divate, D. 2015. Transcutaneous delivery of leflunomide nanoemulgel: mechanistic investigation into physicomechanical characteristics, in vitro anti-psoriatic and anti-melanoma activity. Int. J. Pharm. 487, 148-156. 


\section{ABBREVIATIONS}

nm: Nanometer

BCS: Biopharmaceutics Classification System

PDI: Polydispersity index

LCT: Long chain triglyceride

MCT: Medium chain triglyceride

SCT: Short chain triglyceride

TNF- $\alpha$ : Tumor Necrosis Factor- $\alpha$

IL: Interleukin

Th17: Thymus 17

BP: Blood pressure

CD8: Cluster of differentiation 8

CD4: Cluster of differentiation 4

LL37: Cathelicidin antimicrobial peptides (CAMP)

IFN: Interferons

PRP: Ptyriasisrubra pilaris

HLA-Cw6: human leucocyte antigen- Cw6 serotype receptor

PsA: Psoriatic arthritis

O/W: Oil in water

W/O: Water in oil

UVB: ultraviolet B phototherapy 